\title{
OS IMPACTOS DA CORRUPÇÃO FRENTE À VIOLAÇÃO DOS DIREITOS HUMANOS E DE CIDADANIA: UM DEBATE A SER COMPREENDIDO ${ }^{12}$
}

\author{
Rogério Gesta Leal \\ Universidade de Santa Cruz do Sul - UNISC - Brasil \\ Jonathan Augustus Kellermann Kaercher \\ Universidade de Santa Cruz do Sul - UNISC - Brasil
}

\section{Resumo}

O presente trabalho abordará algumas consequências prejudiciais que a corrupção causa aos Direitos Humanos e de Cidadania. Assim, pretende-se, em um primeiro aspecto, trabalhar com questões conceituais acerca destes direitos para em seguida inter-relacioná-los, demonstrando que eles estão intrínsecos aos seres humanos onde um engloba todos os direitos básicos que correspondem ao ser humano e o outro procura as suas efetivações na sociedade. Nesse contexto, se traz a corrupção como um fator de grande impacto perante estes Direitos, em razão de que as suas atividades ilícitas prejudicam pautas que estão vinculadas aos Direitos Humanos e de Cidadania que passam por um elevado caos em suas rubricas, ante a falta de recursos para o investimento básico em suas estruturas, que são dotadas da necessidade de proteção por parte do Estado, o qual, infelizmente está representado por agentes que ao invés de fazerem jus à finalidade que lhes é incumbida, de zelar e guarnecer estes bens, ao contrário, buscam utilizar destes meios para dar atendimento preferencial aos seus interesses próprios ou de terceiros que estão à sua volta.

Palavras-chave: Cidadania. Corrupção. Direitos Humanos.

\section{I - CONSIDERAÇÕES INICIAIS:}

Pretende-se a título exemplificativo trabalhar com os efeitos nocivos que a corrupção causa aos Direitos Humanos e de Cidadania. Dessa maneira, o presente trabalho tende a abordar alguns aspectos relevantes aos direitos que estão intrínsecos aos seres humanos, ao buscar a compreensão dos motivos que levam à violação destes Direitos.

\footnotetext{
${ }^{1}$ Este artigo é resultado de pesquisas feitas junto ao Centro Integrado de Estudos e Pesquisas em Políticas Públicas - CIEPPP, do Programa de Pós-Graduação em Direito - Mestrado e Doutorado da Universidade de Santa Cruz do Sul-UNISC, e vinculado ao Diretório de Grupo do CNPQ intitulado Estado, Administração Pública e Sociedade, coordenado pelo Prof. Titular Dr. Rogério Gesta Leal, bem como decorrência de projeto de pesquisa intitulado PATOLOGIAS CORRUPTIVAS NAS RELAÇÕES ENTRE ESTADO, ADMINISTRAÇÃO PÚBLICA E SOCIEDADE: causas, conseqüências e tratamentos.

${ }^{2}$ Eixo Temático: Direito e Políticas Públicas.
} 


\section{II - A INTER-RELAÇÃO ENTRE DIREITOS HUMANOS E DE CIDADANIA:}

Os Direitos Humanos tiveram seus caminhos mais importantes no direito egípcio, sendo considerado como um marco teórico inicial dos direitos individuais da pessoa humana, onde eram previstos mecanismos de proteção para os mesmos, trazendo a afirmação de igualdade entre todos os seres humanos, os quais foram sendo aprimorados a partir do surgimento do Código de Hamurabi em 1690 a.C., o qual foi responsável por concretizar os direitos comuns à todos (GUERRA, 2012).

Posteriormente, o Código de Manu trouxe ponderações iniciais de defesa da dignidade e dos direitos da pessoa humana e em sequência a Lei das XII Tábuas consagrou em seu texto algumas questões relacionadas à liberdade, propriedade e proteção dos direitos do cidadão (GUERRA, 2012).

Dessa forma, através de uma constante evolução, que ocorreu em torno de um extenso processo histórico, aos Direitos Humanos, se justapõe um conceito básico e heterogêneo de que eles são derivados do direito natural em razão de serem considerados essenciais a todos os seres humanos, direitos estes que estão interligados com a pessoa e que não necessitam estar positivados, em razão de serem direitos que nascem com as pessoas (GORCZEVSKI, 2005).

Primeiramente era conhecido como os "Direitos do Homem", sendo em 1940 transformado em Direitos Humanos, sendo que a expressão anterior à modificação não incluía os direitos das mulheres (GORCZEVSKI, 2005).

Nesse sentido, entende Guerra (2012) que os Direitos Humanos derivam também de um aparato cristão, tendo valorizado a ideia de dignidade humana a fim de que ela tivesse um Estado justo e aceitável. Nesse sentido, a ideia de dignidade humana deriva do fato de que o homem é a imagem e semelhança de Deus, merecendo, portanto, respeito e dignidade protegida e garantida.

Todos estes relatos históricos trouxeram a matéria variados entendimentos sobre a sua origem, conceito e características, no entanto se entende que toda essa evidente evolução resultou no reconhecimento desses direitos, o que não se constata é um desenvolvimento significativo quando se trata de sua proteção. Dessa forma, se entende que há certa falta de mecanismos de proteção aos Direitos Humanos, em razão de que estão bem amparados e fundamentados (GUERRA, 2012).

Mesmo que haja diferença entre os Direitos Humanos e Fundamentais, ambos muitas vezes se confundem em razão de que os Direitos Humanos são também fundamentais, pois sem eles não é possível a existência do ser humano e, além de fundamentais são também 
universais, ou em outras palavras, podem ser ordenados e devem ser respeitados em qualquer lugar (GORCZEVSKI, 2005).

Nesse sentido, sobre essa questão terminológica, é comum que diariamente se confundam Direitos Humanos e Direitos Fundamentais. No entanto, alerta Guerra (2012) que utilizá-los como sinônimos será um grande equívoco, em razão de eles não correspondem aos direitos naturais, ou melhor dizendo, aos direitos do homem, em razão de que Direitos Humanos são direitos que necessitam ser considerados em uma dimensão espacial e temporal, ou seja, quando e onde se busca a efetivação deles, e da mesma forma se posiciona, assim, em relação aos Direitos Fundamentais, entendendo ser aqueles positivados na norma constitucional.

Além disso, é importante destacar que os Direitos Humanos não são como cláusulas pétreas que não podem ser modificadas ou extintas, em razão de que a construção desses direitos ocorreu em variados momentos históricos, estando em constante evolução, arrecadando, com isso, em cada acontecimento histórico um novo sentido, os quais são modificados e aprimorados com o surgimento de novos direitos (GORCZEVSKI, 2005).

Em concordância com a afirmação de que os Direitos Humanos não são considerados os mesmos desde o seu surgimento, aborda Gallardo (2008) cinco gerações. A primeira geração são aqueles conhecidos como direitos negativos, em que o Estado não poderá intervir, pois nada mais são do que privilégios que o cidadão possui. A segunda geração já se remete aos direitos econômicos, sociais e culturais, que são também vistos como direitos positivos, em razão de que o Estado tem a obrigação de garantir esses direitos. Na terceira geração, incluem-se os direitos garantidos pela Declaração de Argel, que envolve as diferentes etnias e nacionalidades. Na quarta geração estão os direitos do cidadão e da humanidade, sendo tratados com respeito e responsabilidade pelo que eles representam para a sociedade, reconhecendo, com isso, a sua importância. A quinta geração trabalha com a genética humana, em que se deve respeitar a vida nos processos de utilização da vida em processos tecnológicos, podendo assim ser utilizado e explorado sem que se necessite de um retorno financeiro, onde o seu estudo pode ser realizado em apenas benefício da própria raça para a sobrevivência.

No entanto, estas gerações decorrem de um determinado momento e processo histórico, onde se percebe que houve evolução, sendo modificados em conformidade com o momento pelo qual são submetidos. Nessa linha, há quem esclareça qual é o papel dos Direitos Humanos e como ele se altera constantemente. Assim: 
[...] Direitos Humanos têm mais a ver com processos de lutas para abrir e consolidar espaços de liberdade e dignidade humana. Podem ser concebidos como o conjunto de práticas sociais, simbólicas, culturais, e institucionais que reagem contra os excessos de qualquer tipo de poder que impedem aos seres humanos constituírem-se como sujeitos (SÁNCHEZ RUBIO, 2010, p. 17).

Nesse sentido, em virtude da sociedade se modificar constantemente, de fato ela não é mais o que era antes. Além disso, seus fundamentos se deram em torno de mobilizações e movimentos sociais na sociedade civil em desenvolvimento (GALLARDO, 2008).

Esses direitos, ditos universais, existem em razão da qualidade de ser humano do homem, devendo não ser só inerentes a qualquer cidadão, como a sociedade também deve proteger e assegurar a todos, não permitindo a violação dos Direitos Humanos (GUERRA, 2012).

Sobre seu o reconhecimento, mesmo que seja inerente a qualquer pessoa, se deu em face de tratados internacionais, tendo sua consolidação ocorrido em razão de diversas violações do direito do homem com a segunda Guerra Mundial, em meados do século XX, com a finalidade de resgatar o valor do ser humano, que estava perdido em tantos combates e violência. Após este período de holocausto, o processo se fortaleceu e as organizações internacionais se expandiram com o intuito de promover esses direitos.

A partir daí fora elaborada a Carta das Nações Unidas, em 1945, que propôs a criação de um Conselho de Direitos Humanos, consolidando a internacionalização destes direitos por meio de um consenso dos Estados em promovê-los, evitando com isso a guerra e mantendo a paz e a segurança internacional, haja vista que a carta não especificava esses direitos, demonstrando, assim, um problema que fora solucionado em 1948 com a Declaração Universal dos Direitos Humanos, que deu cabo a essas ideias vagas do que são estes Direitos, concretizando-os ao afirmar que basicamente eles são aqueles sem os quais a pessoa é incapaz de desenvolver qualquer de suas capacidades, incluindo personalidade física, intelectual e moral (PIOVESAN, 2013).

Nesse sentido, os Direitos Humanos podem ser considerados como um dos bens mais importantes para o ser humano, os quais devem ser respeitados e assegurados (GUERRA, 2012). Ocorre que segundo Gallardo (2008), há o reconhecimento da existência de um certo abismo entre o que se diz e sobre o que se faz neste campo, em razão de que o Estado é o principal responsável por esta inobservância, uma vez que para ele os Direitos Humanos deveriam ser universais e assegurados a todos. 
Com efeito, é melhor conceber os direitos humanos como um conjunto de pretensões éticas, as quais não devem ser identificados com direitos iguais legislados. Mas essa interpretação normativa não precisa anular a utilidade da ideia de direitos humanos no tipo de contexto no qual eles são comumente invocados. As liberdades que são associadas a direitos específicos podem ser o ponto de enfoque apropriado para o debate. Temos de julgar a plausibilidade dos direitos humanos como um sistema de raciocínio ético e como a base de reinvindicações politicas (SEN, 2000, p. 295).

Além disso, os Direitos Humanos representam uma importante proposta no papel, mas na prática sua violação é rotineira, sendo comum a desconsideração da dignidade da pessoa humana. Porém não é possível imaginar uma pessoa sem dignidade, pois ela está inerente à pessoa e o Estado tem o papel de assegurar uma vida com dignidade para todos (GUERRA, 2012).

Assim, é preciso entender que a Dignidade da Pessoa Humana possui uma posição de fundamento do Estado Democrático de Direito no qual vivemos que está disposto no artigo 1. ${ }^{\circ}$, inciso III, da Constituição Federal de 1988.

[...] um atributo intrínseco de todos os seres humanos, sem exceção, e, desse modo, não se há falar em concessão ou perda da dignidade, mesmo diante de condutas tidas como indignas. É uma qualidade individual, no sentido de que se reporta à pessoa concreta, e impede sacrifícios da dignidade individual em favor do bem geral. É, ainda, algo inegociável e indisponível, de sorte que nem mesmo o próprio sujeito pode a ela renunciar (CORDEIRO, 2012, p. 81).

Com isso, é possível perceber que a garantia da dignidade da pessoa humana resta em parte depreciada, ante uma deficiência de recursos para que os mesmos sejam originados (COSTA; MARTÍN, 2008). E esta dignidade está atrelada à cidadania, uma vez que seus direitos se relacionam em razão da necessidade de serem assegurados direitos semelhantes.

Nesse sentido, se pode dizer que os direitos humanos estão interconectados com a cidadania, de tal maneira que hoje seja incabível dissociá-los. Assim, a noção de cidadania sempre esteve voltada para um agir, para uma conduta que fosse positiva de participação. Segundo Vieira (2001, p. 237) “a cidadania não é uma essência, mas uma construção histórica, que está intimamente ligada às lutas pela conquista dos direitos do cidadão moderno".

Os Direitos humanos, por sua vez, são considerados como direitos básicos, direitos fundamentais internacionalizados. Este último em determinadas épocas era tanto visto como possuidor de direitos negativos (função de defesa), como positivos (função de prestação). Atualmente, são vistos como direitos que exigem do Estado condutas positivas e negativas (direito de participação) (GUERRA, 2012). 
Nesse contexto, pode-se dizer que a cidadania deixou de ser vista de forma restrita, passando a garantir ao cidadão o direito de exigir do Estado condutas negativas e positivas, ou seja, implementando direitos fundamentais individuais e sociais, tornando-se, assim, intimamente ligada aos direitos humanos.

[...] pode-se dizer que a cidadania é constituída tanto por direitos passivos de existência, legalmente limitados, como por direitos ativos que propiciam a capacidade presente e futura de influenciar o poder político. [...] pessoas e coletividades podem possuir seus próprios imperativos morais, costumes ou mesmo direitos específicos, mas estes só se tornarão direitos de cidadania se forem universalmente aplicados e garantidos pelo Estado. [...] por sua vez, Turner considera a cidadania como um conjunto de práticas políticas, econômicas, jurídicas e culturais que definem uma pessoa como membro competente da sociedade (VIEIRA, 2001, p. 35).

Ademais, ambos os direitos a serem conquistados são frutos de um processo histórico de conquistas, avanços e mudança de comportamento, não podendo, assim, ser entendidos como direitos subjetivos inerentes aos indivíduos.

Os direitos humanos, neste contexto, nada mais são do que direitos fundamentais da pessoa humana, pois são imprescindíveis como garantia da participação plena na vida social, se encontrando aí, o elo que liga a concepção de cidadania aos direitos humanos (GUERRA, 2012).

Se considerarmos, assim, que a cidadania é o direito de participação na sociedade e que para se realizar o seu efetivo exercício deve o cidadão ser resguardado de direitos básicos, tais como a vida, a moradia, a educação, a informação, dentre outros e considerando que estes direitos são direitos básicos de qualquer ser humano, logo se pode concluir que a violação de direitos humanos se redunda em prejuízo ao íntegro exercício da cidadania. Assim:

A cidadania é um direito a ter direitos, pois a igualdade em dignidade e direitos humanos não é um dado. É um construído na convivência coletiva, que requer o acesso ao espaço público. É este acesso que permite a construção de um mundo comum através do processo de asserção dos direitos humanos (ARENDT, 1993, p. 299).

Complementando, se pode dizer que a cidadania passou a se constituir em todos os direitos que foram conferidos ao cidadão, não apenas em razão do fato de a dignidade exigir a efetivação desses direitos, mas em razão do fato de que ela é própria condição para o exercício da cidadania (CAMPELLO; SILVEIRA, 2016). 
“A prática da cidadania depende do fato da reativação da esfera pública, em que indivíduos podem agir coletivamente e se empenhar em deliberações comuns sobre todos os assuntos que afetam a comunidade política" (VEIRA, 2001, p. 72).

Com isso, a cidadania possui novos desafios, sendo preciso uma abordagem abrangente que seja capaz de compreender a realidade e os problemas sociais. Assim, se enfatiza que, em suas respectivas dimensões, os direitos humanos englobam os direitos essenciais dentro da sociedade, ou seja, criam oportunidades claras para o desenvolvimento da cidadania, além de se contribuir para uma melhor efetividade (CAMPELLO; SILVEIRA, 2016).

Portanto, se deve reafirmar o compromisso de buscar a garantia dos Direitos Humanos e de Cidadania, em razão de que a cada dia a sua violação aumenta de forma gradual com o reflexo de expansivas atividades que se sobrepõem na sociedade, tornando-se, com isso, um desafio sua efetivação em escala global, restando claro que essa constante violação é o resultado dos momentos vividos atualmente, dentre eles, o da expansiva prática corruptiva que gera efeitos multifacetados que afetam toda uma sociedade possuidora de Direitos Humanos e de Cidadania. No próximo item, passa-se a trabalhar com os impactos desta patologia perante estes Direitos que carecem de proteção principalmente do Estado.

\section{IV - NÃO HÁ LIMITES PARA OS IMPACTOS NEGATIVOS DA CORRUPÇÃO: OS DIREITOS HUMANOS E DE CIDADANIA COMO ALVO}

Inicialmente, salienta-se que a corrupção é um fenômeno definido pela Organização das Nações Unidas como sendo o "abuso da função pública para ganho pessoal direto ou indireto", enquanto ao dicionário Houaiss é um "ato ou efeito de subornar uma ou mais pessoas em causa própria ou alheia, geralmente com oferecimento de dinheiro" (PETRELLUZZI; RIZEK JÚNIOR, 2014, p. 19-20).

\footnotetext{
Vulgarmente, conceituar corrupção é uma tarefa quase impossível, pois o termo comporta inúmeros significados e extensa gama de consequências. Há, no entanto, um ponto em comum: trata-se de algo negativo; jamais positivo. Em dicionários, as definições não variam e perfilam o mesmo contexto: decompor, depravar, desmoralizar, subornar, tornar podre, enfim, destroçar algo. (NUCCI, 2015, p. 01).
}

Nesse sentido, as condutas corruptivas são entendidas como extremamente complexas, onde se envolvem agentes públicos e privados, pessoas físicas e pessoas jurídicas, sendo difícil encontrar uma definição ou até mesmo um único conceito que venha a contemplar todas as possibilidades que o vocabulário encerra (PETRELLUZZI; RIZEK JÚNIOR, 2014). 
Assim, para fins de análise do tema, o conceito de corrupção é o seguinte: trata-se de toda e qualquer vantagem obtida pelos agentes públicos no exercício das funções que cause prejuízo aos bens, serviços e dos interesses do Estado (LIVIANU, 2014, p. 25).

Nesse contexto, observa Leal (2013) que na tradição do pensamento político ocidental, não há um único consenso sobre o que vem a ser corrupção, ou seja, não há uma definição nesse sentido. Portanto, não se pode falar de uma única Teoria Política de Corrupção, pois existem diferentes abordagens sobre o tema, através de determinados marcos teóricos e filosóficos específicos.

La corrupción tiene semejanza com la palabra corrosión, efectivamente, la acción corrupta se puede dar em forma instantánea, pero tras de ella hay todo um proceso en el que la conciencia y la voluntad han sido poco a poco corroídas. Incluso las fuentes originales de esta tendencia perversa trascienden nuestro momento histórico ${ }^{3}$ (LLACA, 2015, p. 168).

Em outras palavras, este fenômeno é um difícil debate de se compreender e definir, haja vista que possui diversos campos de conhecimento, pois inúmeros são os conceitos que esclarecem esta prática. Logo, se pode também entender que a corrupção vem a surgir como uma ideia de destruição e degradação.

[...] a corrupção se apresenta como um meio de degradação do interesse público em prol da satisfação do interesse privado. O agente público, apesar de exercer suas funções no âmbito de uma estrutura organizacional destinada à consecução do bem comum, desvia-se dos seus propósitos originais e passa atuar em prol de um interesse privado bipolar, vale dizer, aquele que, a um só tempo, propicia uma vantagem indevida para si próprio e enseja um benefício para o particular que compactuou com a prática corrupta (GARCIA, 2013, p. 68).

E este tipo de benefício não passa a ser somente econômico. No âmbito político, por exemplo, a exploração do prestígio e a conduta desviada com o intuito de obter vantagem de natureza política, mesmo que não tenha finalidade econômica caracteriza igualmente a corrupção (PETRELLUZZI; RIZEK JÚNIOR, 2014). E isso não ocorre somente em esfera pública, mas também em esfera privada, como é o caso de empresas privadas, que são corrompidas por meio de seus funcionários que se utilizam do cargo que ocupam a fim de obter ganhos pessoais próprios ou alheios.

\footnotetext{
${ }^{3}$ A corrupção tem semelhança com corrosão, onde de fato a ação corrupta pode se dar instantaneamente, mas por trás dela há todo um processo em que a consciência terá sido gradualmente corroída. As fontes originais desta tendência vão além do nosso momento histórico.
} 
Logo, dá para se considerar que, quem para se firmar no controle utiliza, ilegalmente, de sua função, mesmo que não venha lograr obter vantagem econômica, está também agindo de maneira corrupta. Ademais, a ausência de consciência coletiva somada à supremacia do interesse privado sobre o público é igualmente um poderoso elemento de estímulo à corrupção, tornando-se socialmente aceitável. (GARCIA, 2013). Com isso, dá para se estabelecer o entendimento de que:

[...] o problema da corrupção, assim, é amplo, envolvendo, na verdade, qualquer locupletamento indevido decorrente da prática de ato ilegal ou mesmo antiético para beneficiar alguém ou facilitar alguma atividade, ainda que legítima de outrem, ou ainda, comportar-se de maneira indevida para obter algum benefício para si ou para outrem, ainda que sem conteúdo econômico. Nesse sentido amplo, por exemplo, também seriam atos de corrupção o do empregado que assina o livro de presença por outro ou o funcionário que pula a catraca controladora de entradas e saídas para burlar a vigilância de horário de expediente. (GRECO FILHO, V.; RASSI, J. D.; 2015, p. 16)

O fenômeno da corrupção, portanto, é definido como um tema amplo e difícil de compreender, em razão de abranger variados campos do conhecimento, havendo, nesse sentido, variados conceitos que esclarecem o que vem a ser esta prática. Logo, a corrupção tanto pode sugerir a ideia de destruição como a de mera degradação, assumindo uma perspectiva natural, como evento efetivamente apurado na realidade fenomênica, ou meramente valorativa.

Assim, a corrupção é entendida como uma relação social, que é estabelecida por duas pessoas ou dois grupos de pessoas, compostos por corruptos e corruptores, com a intenção de transferir renda ilegal, tanto da sociedade, como de fundo público, para a concretização de fins exclusivamente privados.

Relação essa, que também abrange a troca de favores estabelecida entre os grupos ou pessoas e, comumente, ao pagamento dos corruptos com a utilização de propina ou de quaisquer outros tipos de incentivos, compactuados pelas regras do jogo e, em consequência, pelo sistema de incentivos que delas insurgem.

Corrupção é o comportamento que se desvia dos deveres formais de uma função pública devido a interesses privados (pessoais, familiares, de grupo fechado) de natureza pecuniária ou para melhorar o status, ou que viola regras contra o exercício de certos tipos de comportamento ligados a interesses privados (KLITGAARD, 1994, p. 40).

Ademais, as histórias que são difundidas sobre o tema da corrupção, buscam esclarecêla como um fenômeno multifacetário, cujos aspectos são culturais, políticos, sociais, 
institucionais e econômicos. É definida, como um padrão de comportamento que se afasta de normas predominantes em um dado contexto, sendo que este comportamento é associado a uma particular motivação que, conforme tratado anteriormente, é o ganho privado a expensas do público (BREI, 2016). E as suas consequências são inúmeras, dentre elas:

[...] la corrupción ha provocado en la administración pública desgracias semejantes: pérdida de efectividad, aumento de costos en la burocracia y de gastos en la sociedad; resultados fuera de control y los programados absolutamente precarious. En un gobierno corrupto, entrar a una oficina pública es dar un paso en el abismo; el riesgo y la incertidumbre campean. Lá pérdida de reglas y el dominio de la informalidad convierten a la tramitología en una película de terror, todo puede suceder (LLACA, 2015, p. 168) ${ }^{4}$.

A par disso, é necessário ressaltar que a corrupção é trazida por meio de temas centrais no processo comunicativo de globalização, em que se buscam unir esforços internacionais, tanto para o seu controle, quanto para uma possível execução, difusão e fortalecimento de ferramentas preventivas e de diagnósticos que sejam eficazes, visando, com isso, objetivos comuns aos povos civilizados e democráticos (OSÓRIO, 2013).

É interessante frisar que a tarefa de buscar a inclusão social das parcelas da população menos favorecidas encontra dificuldades na progressiva carência de recursos financeiros, não só no nosso País, como em grandes potências mundiais, como os Estados Unidos. Mas, no Brasil, o problema é mais crônico, pois, além da grande desigualdade social com a qual convivemos, deparamo-nos com altos índices de corrupção praticada por agentes que deveriam estar a serviço da sociedade e não de interesses pessoais. (BOTELHO, 2010, p. 120)

Em verdade, quando a corrupção se encontra espalhada em todo o corpo politico e tolerada pela comunidade, as pessoas mais necessitadas, por consequência, sentem os efeitos desta mazela social de forma mais direta, em razão de que as estruturas dos poderes instituídos se ocupam, por vezes com questões que lhes rendam vantagens, seja de grupos, seja de indivíduos, do que com interesses públicos vitais existentes (LEAL, 2013). Em consequência disso:

\footnotetext{
${ }^{4}$ A corrupção tem provocado na administração pública desgraças semelhantes: perda de efetividade, aumento de custos da burocracia e de gastos com a sociedade; resultados fora de controle e programas absolutamente precários. Em um governo corrupto, entrar em um setor público é dar um passo ao abismo; o risco e a incerteza predominam. A perda de regras e o domínio da informalidade convertem a burocracia em um filme de terror, onde tudo pode acontecer.
} 
[...] hospitais públicos deixam de atender pacientes na forma devida porque são desviados recursos da saúde para outras rubricas orçamentárias mais fáceis de serem manipuladas e desviadas como prática de suborno e defraudação; famílias em situação de pobreza e hipossuficiência material não podem se alimentar porque os recursos de programas sociais são desviados para setores corruptos do Estado e da Sociedade Civil; as escolas públicas não têm recursos orçamentários à aquisição de material escolar em face dos desvios de recursos para outros fins, e os alunos ficam sem condições de formação minimamente adequadas (LEAL, KAERCHER, 2015, p. 02).

Infelizmente, quando as pessoas se tornam mais conscientes dos danos que a corrupção provoca a interesses públicos e mesmo privados, elas ficam sensibilizadas com medidas de enfrentamento e tratamento desta patologia (LEAL, 2014). Em razão de ser uma patologia manifesta em grande parte do mundo, deixou de ser somente uma preocupação nacional. Assim, ao longo dos anos a corrupção se tornou uma preocupação predominantemente nacional ou regional, transformando-se em um tema de debate global.

\footnotetext{
Em menos de meia década a reação mundial contra a corrupção tomou de assalto o cenário político internacional. Governos caíram. Partidos há muito no poder foram expulsos do comando. Presidentes, primeiros-ministros, parlamentares e caciques corporativos antes poderosos foram questionados/investigados, à exaustão, por promotores, e engrossam os registros de processo judiciais. Itália, França, Japão, Coréia do Sul, Índia, México, Colômbia, Brasil, África do Sul: nenhuma região escapou e pouquíssimos países estão imunes. (GLYNN, P. KOBRIN, S. J.; NAÍM, M., 2002, p. 27)
}

Diante disso, depreende-se que a corrupção tem efeitos significativos sobre a democracia, no sentido de que ela rompe com os pressupostos fundamentais do regime, tais como a igualdade política e a participação. Minimiza a influência da população no processo de tomada de decisões, seja em razão de fraudes nos processos decisórios, como nas eleições, seja pela desconfiança e pela suspeita que ela vem a gerar entre os próprios cidadãos com relação ao governo e às instituições democráticas. Acaba, por fim, minimizando a transparência das ações dos governantes (MENEGUELLO, 2011).

A corrupção não pode ser considerada como um fenômeno exclusivamente de uma sociedade ou de um momento de seu desenvolvimento, conforme sugerem algumas teorias evolutivas modernizantes, haja vista que ela está corrente nas formações sociais mais distintas, consoante comprovam trabalhos publicados nos últimos anos nas ciências sociais (BEZERRA, 1995).

Além do exposto, as práticas definidas como corruptas ou, em outras palavras, corruptoras, não são idênticas, pois sofrem uma variação significativa. De fato, o fenômeno da 
corrupção possui uma dimensão legal, histórica, e cultural que não pode ser negligenciada, quando se pretender estudá-la (BEZERRA, 1995).

\begin{abstract}
A luta contra a corrupção é complicada por inúmeros fatores; porém, a dificuldade básica é definir o que seja a corrupção, independentemente se sua definição legal, que varia enormemente de uma sociedade para a outra. $O$ termo tem sido empregado para se referir a um amplo espectro de ações. Pode ser usado para designar ações ilegais ou antiéticas perpetradas por pessoas em posição de autoridade ou de confiança no serviço público, ou por cidadãos e empresas em sua relação com os agentes públicos. Consequentemente, parece claro que a luta contra esse mal não pode ser confinada ao setor público e restringir-se a medidas punitivas, penais e administrativas, dirigidas a agentes individuais, pois não há dúvida de que a corrupção interna quase sempre depende da relação entre os agentes públicos e os cidadãos. (SILA, 2008, p. 575).
\end{abstract}

A corrupção, portanto, é um dos assuntos mais debatidos no processo comunicativo de globalização, em que se procuram reunir esforços e auxílios internacionais, para o seu combate, bem como para a implementação e o fortalecimento de ferramentas preventivas e de diagnósticos precisos, pois este debate é um objetivo comum frente aos povos civilizados e democráticos (OSÓRIO, 2013).

No entanto, uma das respostas que parece ser mais viável a isto tudo, é a de o Estado deve procurar fomentar a utilização de mecanismos de "controle" já existentes, bem como a criação de novos meios que auxiliem na minimização de atos corruptivos. A partir daí, como já está acontecendo, se entende que algumas mudanças acontecerão, mesmo que sejam vagarosamente conquistadas.

\footnotetext{
É interessante frisar que a tarefa de buscar a inclusão social das parcelas da população menos favorecidas encontra dificuldades na progressiva carência de recursos financeiros, não só no nosso País, como em grandes potências mundiais, como os Estados Unidos. Mas, no Brasil, o problema é mais crônico, pois, além da grande desigualdade social com a qual convivemos, deparamo-nos com altos índices de corrupção praticada por agentes que deveriam estar a serviço da sociedade e não de interesses pessoais. (BOTELHO, 2010, p. 120)
}

Dessa forma, em sua origem grega, o conceito de corrupção aponta para dois lados. O primeiro refere-se a algo que se quebra através de um vínculo, que se degrada no momento em que ocorre a sua ruptura, sendo suas consequências consideráveis. De outro lado, quebrase o princípio da confiança, além do elo que permite ao cidadão se associar para interferir na vida de seu país, ocorrendo a degradação do sentido do público. Em razão disso, nas ditaduras a corrupção possui funcionalidade, que serve para garantir a dissipação da vida pública. Em 
democracias, seu efeito é contrário, servindo para dissolver princípios políticos que baseiam as condições para o exercício da virtude do cidadão (STARLING, 2008).

Por outro lado, a corrupção também atinge os Direitos Humanos e de Cidadania através da via dos comportamentos que são corruptivos de algumas pessoas, evidenciando a falha estatal de se evitar isto. Assim, quando alguém pratica o suborno para obter algo que lhe seja necessário, atua em conduta que viola os sistemas existentes para cada situação, como é o caso, por exemplo, de se efetuar pagamento ilegal para conseguir um órgão humano, ou o desvio de rubricas orçamentárias de saúde e educação para a utilização de fins ilícitos. Nestes casos, se está afetando o sistema de saúde e de educação.

Veja-se, com isso, que neste caso ocorre a violação do direito de igualdade que a Constituição Federal de 1988 garante, pois, aqui, se dá tratamento desigual a pessoas em razão do serviço ou atividade que se deveria atender de forma isonômica a todos (PRESTON; SAMFORD, 2002).

Desse modo, todos os indivíduos são dotados de Direitos Humanos e de Cidadania, e todos os Estados estão obrigados em garantir que a população goze desses direitos. Logo, cada Direito Humano e de Cidadania possui em favor de si algumas específicas obrigações por parte dos Estados e mesmo por parte dos indivíduos entre si. Ocorre que para as pessoas usufruírem destes Direitos Fundamentais, precisa o Estado cuidar para que haja condições favoráveis para tanto, assim é que se diz que os Estados necessitam fazer cumprir todos os direitos de respeito e proteção.

The obligation to respect requires states to refrain from interfering directly or indirectly with the enjoyment of human rights. The obligation to protect requires states to prevent third parties from interfering in any way with the enjoyment of human rights. States must also fulfill human rights, thus have to take positive measures to assist individuals and communities in enjoying those rights ${ }^{5}$ (GARDNER, 2002, p. 29).

Com isso, se percebe que existe uma clara violação dos Direitos Humanos e de Cidadania, quando um ato ou até mesmo uma omissão do Estado não se encontram em conformidade com suas obrigações de respeito, efetivação e proteção daqueles direitos que estejam sob sua tutela. No entanto, para que se tenha uma maior clareza em algumas questões,

\footnotetext{
${ }^{5}$ A obrigação de respeito exige que os Estados se abstenham de interferir direta ou indiretamente sobre os direitos humanos. A obrigação de proteger requer que os estados evitem que terceiros interfiram de algum modo no gozo destes direitos. Os Estados também devem cumprir os direitos humanos, assim, tem de tomar medidas positivas para ajudar os indivíduos e as comunidades em apreciar esses direitos.
} 
se faz necessário determinar que as condutas sejam buscadas por parte dos Estados e que estejam relacionadas a cada Direito.

Para isso, depende-se dos precisos termos e condições das responsabilidades dos Estados perante os Direitos Humanos e de Cidadania, e em face do argumento normativopositivista de obrigatoriedade legal das instituições estatais que prevalece no país e que geram reflexos na dificuldade dogmática do reconhecimento de vinculatividade daqueles Direitos que estão vigentes em Tratados e Pactos Internacionais, ainda que não estejam plenamente incorporados na legislação nacional.

Em sendo assim, para os fins de se determinar se as práticas corruptivas violam os Direitos Humanos e de Cidadania se faz necessário, em primeiro lugar, procurar reconhecer quais são as ações ou omissões que são exigidas do Estado para proteger, efetivar e respeitar esses Direitos, motivo pelo qual o claro entendimento dos objetivos e conteúdos destes Direitos é necessário para a delimitação dessas responsabilidades estatais.

Além disso, a prática corruptiva necessita ser sopesada no contexto dos objetivos e conteúdos dos Direitos Humanos e de Cidadania envolvidos, averiguando se ela pode prejudicar tais conteúdos de forma direta ou indireta, bem como se o Estado deixa de concluir com as obrigações de proteção, efetivação e respeito.

Portanto, não resta dúvidas de que a corrupção está claramente relacionada à transgressão de Direitos Humanos e de Cidadania, especialmente quando os atos corruptivos forem utilizados como sinônimos de violação do sistema jurídico (como é a prática do suborno), que não afeta por si só a ordem jurídica posta, mas sim provoca nefastos impactos que se situam na rede de direitos e garantias vigentes.

\section{IV - CONSIDERAÇÕES FINAIS:}

Inicialmente, cabe salientar que os Direitos Humanos são considerados como os direitos e liberdades básicos para todos os seres humanos. Ademais, seu conceito está ligado com a ideia de liberdade de pensamento, expressão e igualdade. São essenciais para todos independentemente de raça, sexo, cor religião, etnia, dentre outros afins.

Os Direitos de Cidadania, por sua vez, são considerados como o exercício dos direitos e deveres civis, sociais e políticos. Assim, praticar a cidadania, por exemplo, é ter a consciência de que os seus direitos e obrigações sejam colocados em prática, para que os membros de uma sociedade possam desfrutar dos Direitos Humanos, Fundamentais, tanto em um nível individual, coletivo ou institucional. 
Nesse sentido, os Direitos de Cidadania estão conectados com os Direitos Humanos em razão de que a noção de cidadania sempre está inclinada para um agir, ou seja, para uma conduta que seja positiva de participação e que busque a efetivação dos Direitos Humanos. Aí que está, portanto, o vínculo entre estes dois conceitos, onde um engloba todos os direitos básicos que correspondem ao cidadão e o outro procura as suas efetivações através do direito posto.

Nesse contexto, se traz a corrupção como um fator de grande impacto perante estes Direitos, em razão de que as suas atividades ilícitas prejudicam pautas que estão vinculadas aos Direitos Humanos e de Cidadania que passam por um elevado caos em suas rubricas, ante a falta de recursos para o investimento básico em suas estruturas, que são dotadas da necessidade de proteção por parte do Estado, o qual, infelizmente está representado por agentes que ao invés de fazerem jus à finalidade que lhes é incumbida, de zelar e guarnecer estes bens, ao contrário, buscam-se utilizar destes meios para dar atendimento preferencial aos seus interesses próprios ou de terceiros que estão à sua volta.

Em razão disso, é que se faz necessária uma nova implementação de mecanismos que assumam um modo de transparecer estas condutas, penalizando seus infratores com medidas de inibição desses malfeitos. Ao lado disso, a fomentação de políticas públicas de conscientização aos agentes públicos e políticos poderá ser um pontapé inicial para o controle desta patologia que assola os direitos individuais e indisponíveis do cidadão.

\title{
THE IMPACTS OF CORRUPTION AGAINST THE VIOLATION OF HUMAN RIGHTS AND CITIZENSHIP: A DEBATE TO BE UNDERSTANDED
}

\begin{abstract}
This paper will address some harmful consequences that corruption causes to the Human Rights and Citizenship. Thus, it is intended, in a first aspect, working with conceptual questions about these rights to then inter-relate them, showing that they are intrinsic to human beings where one includes all the basic rights that correspond to human and other demand their functionings in society. In this context, it brings corruption as a major impact factor before these rights, on the grounds that their illegal activities detrimental agendas that are linked to human rights and citizenship to go through a high chaos in its lines, given the lack of resources for basic investment in their structures, which are endowed with the need for protection from the state, which unfortunately is represented by agents instead of doing justice to the purpose to them responsible, to watch over and garnish these assets, the Instead, they seek to use these means to give preferential treatment to their own interests or third parties who are around them.
\end{abstract}

Key Words: Citizenship. Corruption. Human Rights. 


\section{Referências}

ARENDT, Hannah. The origins of totalitarianism. Nova York: Harcourt Brace Jovanovitch, 1993.

BEZERRA, Marcos Otávio. Corrupção: um estudo sobre poder público e relações pessoais no Brasil. Rio de Janeiro: Relume-Dumará, 1995.

BOTELHO, Ana Cristina Melo de. Corrupção política: uma patologia social. Belo Horizonte: Fórum, 2010.

BREI, Zani Andrade. Corrupção: dificuldades para definição e para um consenso. Disponível em: <file://C:/Users/Usu\%C3\%A1rio/Downloads/8128-17567-1-PB.pdf>. Acesso em: 24 maio 2016.

CAMPELLO, Lívia Gaigher Bósio; SILVEIRA, Vladimir Oliveira da. Cidadania e direitos humanos. Disponível em: <http://faa.edu.br>. Acesso em: 14 julho 2016.

CORDEIRO, Karine da Silva. Direitos fundamentais sociais: dignidade da pessoa humana e mínimo existencial. Porto Alegre: Livraria do Advogado, 2012.

COSTA, Marli M.M. da. MARTÍN, Núria Belosso. Diálogos jurídicos entre Brasil e Espanha: da exclusão social aos direitos sociais. Porto Alegre: Imprensa Livre, 2008.

GALLARDO, Helio. Teoria Crítica: Matriz y possibilidad de derechos humanos. Murcia: David Sanchez Rubio, 2008.

GARCIA, Emerson. Improbidade administrativa. 7. Ed., rev. ampl. e atual. São Paulo: Saraiva, 2013.

GARDNER, John. Defining Corruption. In HEIDENHEIMER, Arnold J.; JOHNSTON, Michael, (eds.). Political Corruption: Concepts \& Contexts. New Brunswick: Transaction Publishers, 2002.

GLYNN, P. KOBRIN, S. J.; NAÍM, M. A globalização da corrupção. In: ELLIOTT, Kimberly Ann. (Org.); A corrupção e a economia global. Brasília: Editora Universidade de Brasília, 2002.

GORCZEVSKI, Clóvis. Direitos Humanos: dos primórdios da humanidade ao Brasil. Porto Alegre: Imprensa Livre, 2005.

GRECO FILHO, V.; RASSI, J. D.; O combate à corrupção e comentários à Lei de Responsabilidade das Pessoas Jurídicas (Lei n. 12.846, de $1^{\circ}$ de agosto de 2013) Atualizado de acordo com o Decreto n. 8.420, de 18 de março de 2015. São Paulo: Saraiva, 2015.

GUERRA, Sidney. Direitos Humanos e Cidadania. São Paulo: Atlas, 2012.

KLITGAARD, R. A corrupção sob controle. Rio de Janeiro: Jorge Zahar Editora, 1994. 
LEAL, Rogério Gesta. Dimensões pragmáticas da relação entre corrupção e direitos fundamentais. In: GORCZEVSKI, Clóvis (Org.). Direitos humanos e participação política. Porto Alegre: Imprensa Livre, 2014.

; KAERCHER, Jonathan Augustus Kellermann. Patologias corruptivas e a sua relevância para a tutela dos direitos humanos. In: XI Seminário Nacional Demandas Sociais e Políticas Públicas na Sociedade Contemporânea da Universidade de Santa Cruz do Sul - UNISC. Disponível em: <file://C:/Users/Usu\%C3\%A1rio/Downloads/14297 9168-1-PB\%20(1).pdf>. Acesso em: 24 maio 2016.

Patologias corruptivas nas relações ente Estado, administração pública e sociedade: causas, consequências e tratamentos. Santa Cruz do Sul: EDUNISC, 2013.

LIVIANU, Roberto. Corrupção - Incluindo a Lei Anticorrupção, 2ª . Ed. São Paulo: Quartier Latin, 2014.

LLACA, Edmundo González. La corrupción y la ética. Disponível em: <file:///C:/Users/Usu\%C3\%A1rio/Downloads/LLaca\%20(1).pdf >. Acesso em: 11 agosto 2015.

MENEGUELLO, Rachel. O lugar da corrupção no mapa de referências dos brasileiros: os aspectos da relação entre corrupção e democracia. In: AVRITZER, L.; FILGUERAS, F.; (Org.) Corrupção e sistema político no Brasil. Rio de Janeiro: Editora Civilização Brasileira, 2011.

NUCCI, Guilherme de Souza. Corrupção e anticorrupção. Rio de Janeiro: Forense, 2015.

OSÓRIO, Fábio Medina. Teoria da Improbidade administrativa: má gestão pública: corrupção: ineficiência. 3.ed. São Paulo: Editora Revista dos Tribunais, 2013.

PETRELLUZZI, Marco Vinicio; RIZEK JUNIOR, Rubens Naman. Lei Anticorrupção: origens, comentários e análise da legislação correlata. São Paulo, Saraiva, 2014.

PIOVESAN, Flávia. Direitos Humanos e Direito Constitucional Internacional. 14 ed., São Paulo: Saraiva, 2013.

PRESTON, Noel, and SAMPFORD, Charles (eds.). Encouraging Ethics and Challenging Corruption. Sydney: Federation Press, 2002.

SÁNCHEZ RUBIO, David. Fazendo e desfazendo direitos humanos/ David Sánchez Rubio; tradução, Clovis Gorczevski. Santa Cruz do Sul: EDUNISC, 2010.

SEN, Amartya. Desenvolvimento como liberdade. São Paulo: Cia das Letras, 2000.

SILA, Jorge da. Criminologia Crítica - Segurança Pública e Polícia. Rio de Janeiro: Forense, 2008. 
STARLING, Heloisa Maria Murgel. Ditadura Militar. In AVRITZER, Leonardo (org.).

Corrupção: ensaios e críticas. Belo Horizonte: UFMG, 2008.

VIEIRA, Liszt. Cidadania e Globalização. Rio de Janeiro: Record, 1997.

Os argonautas da cidadania: sociedade civil na globalização. Rio de Janeiro:

Record, 2001.

\section{Sobre os autores:}

Rogério Gesta Leal é Desembargador do Tribunal de Justiça do Estado do Rio Grande do Sul, Doutor em Direito. Professor Titular da UNISC. Professor da UNOESC. Professor Visitante da Università Túlio Ascarelli - Roma Trè, Universidad de La Coruña - Espanha, e Universidad de Buenos Aires. Professor da Escola Nacional de Formação e Aperfeiçoamento da Magistratura - ENFAM. Membro da Rede de Direitos Fundamentais-REDIR, do Conselho Nacional de Justiça-CNJ, Brasília. Coordenador Científico do Núcleo de Pesquisa Judiciária, da Escola Nacional de Formação e Aperfeiçoamento da Magistratura - ENFAM, Brasília. Membro do Conselho Científico do Observatório da Justiça Brasileira. Coordenador da Rede de Observatórios do Direito à Verdade, Memória e Justiça nas Universidades brasileiras - Secretaria de Direitos Humanos da Presidência da República. E-mail: rleal@unisc.br

Jonathan Augustus Kellermann Kaercher é Advogado. Mestrando no Programa de Pós-Graduação em Direito com Conceito 5 na Capes - Mestrado e Doutorado da Universidade de Santa Cruz do Sul/RS UNISC (2015-2016) com Taxa PROSUP/CAPES. É integrante do grupo de pesquisa Patologias Corruptivas nas relações entre Estado, Administração e Sociedade: causas, consequências e tratamentos, coordenado pelo Professor Doutor Rogério Gesta Leal, vinculado ao PPGD-UNISC e certificado pelo CNPq. E-mail: jonathanaugustus@ hotmail.com 